\title{
Chronic and infectious diseases in Aboriginal and Torres Strait Islander peoples
}

\author{
Patricia M. Morton ${ }^{\mathrm{A}}$, Jenny M. Hunt ${ }^{\mathrm{B}}$ \\ and Richard J. Weston ${ }^{\mathrm{C}}$ \\ ${ }^{\mathrm{A}} N \mathrm{SW}$ Public Health Officer Training Program, \\ NSW Department of Health \\ ${ }^{\mathrm{B}}$ Aboriginal Health and Medical Research Council of NSW \\ ${ }^{\mathrm{C}}$ Maari Ma Health Aboriginal Corporation
}

(Note: The word Aboriginal is used throughout to refer to Aboriginal and Torres Strait Islander peoples.)

Australia is a rich country with high living standards and a world-class health system. According to the United Nations Development Program, Australia is ranked third in the world in terms of human development and fifth in the world in terms of life expectancy. ${ }^{1}$ However, the benefits of high living standards are not evenly distributed to all Australians. Current life expectancy for Aboriginal Australians is 59 years for men and 65 years for women, 17 years less than non-Aboriginal Australians. Compared to the life expectancy of populations in countries around the world, the life expectancy of Aboriginal Australians ranks 123rd (after Bangladesh and Bolivia). ${ }^{1}$ Furthermore, the gap in life expectancy between Aboriginal and nonAboriginal Australians is larger than the gap between indigenous and non-indigenous peoples in similarly developed countries such as the United States, Canada and New Zealand. ${ }^{2}$

According to data from the Australian Bureau of Statistics for Queensland, South Australia, Western Australia and the Northern Territory, the five most common causes of death for Aboriginal Australians between 1999 and 2003 were: diseases of the circulatory system; external causes (injury and self-harm); neoplasms; respiratory diseases; diabetes and chronic kidney disease. Although these are also causes of death for other Australians, Aboriginal Australians are four times more likely to die as a result of diabetes than non-Aboriginal Australians and twice as likely to die of external causes and chronic kidney disease. $^{3}$

Not only do Aboriginal Australians die younger, they also become ill much more often than non-Aboriginal Australians. In fact, hospitalisation rates for Aboriginal Australians are twice that for non-Aboriginal Australians. Aboriginal Australians are hospitalised for care involving dialysis (for the treatment of chronic kidney disease) at 12 times the rate of non-Aboriginal Australians. In addition,
Aboriginal Australians are hospitalised for endocrine, skin and respiratory conditions, external causes, circulatory diseases, infectious and parasitic diseases, mental and behavioural causes and complications of pregnancy at between 1.5 and 2.9 times the rate of non-Aboriginal Australians. ${ }^{3}$ Note that hospitalisation data have limitations as measures of morbidity: disparities between morbidity in Aboriginal and non-Aboriginal Australians are likely to be greater than indicated by these data. The premature mortality and higher morbidity in Aboriginal Australians are mainly due to chronic diseases primarily attributable to social, economic and educational disadvantage, with associated higher prevalence of negative health-related behaviours.

\section{Addressing the health needs of Aboriginal peoples}

Aboriginal Community Controlled Health Services operating in New South Wales (NSW) have developed best practice models for delivering health services to Aboriginal peoples.

The Aboriginal Health and Medical Research Council of NSW (AH\&MRC) is the recognised peak body and voice of Aboriginal communities on health matters for over 50 Aboriginal Community Controlled Health Organisations in NSW. The AH\&MRC represents and supports its member Aboriginal community controlled health services, develops and delivers public health programs, provides accredited training through its Aboriginal Health College and runs a human research ethics committee registered with the National Health and Medical Research Council.

Important principles of good practice for delivering health services to Aboriginal people advocated by the AH\&MRC are: community control and engagement; a focus on capacity building; an integrated, coordinated approach; using evidence; and forming partnerships. Recent public health projects undertaken by the AH\&MRC include: research and resource development for sexually transmitted infections and bloodborne viruses; policy work on drug and alcohol harm minimisation; chronic disease workshops focused on promoting adult health checks; developing an ongoing chronic disease program; exploring and responding to gambling issues; and convening a national lupus workshop.

Maari Ma is an Aboriginal Community Controlled Health Service that manages all health services in the western third of the Greater Western Area Health Service (not 
including Broken Hill). In order to address the high prevalence of chronic disease, the service has developed a chronic disease strategy that identifies essential elements needed to deliver high quality chronic disease care including: evidence-based practice; system and organisational approaches to care; record and recall systems; communication and cultural skills; multidisciplinary approaches to clinical care; and population approaches (for example, across the lifespan and addressing the social determinants of health). The three key activities of the strategy are: prevention (health promotion and supportive networks); early detection (screening, health checks and control of risk factors); and management (continuing care, maintenance and self-management).

\section{References}

1. United Nations Development Program. Human Development Report 2006. Palgrave Macmillan: Basingstoke, UK; 2006. Available at: http://hdr.undp.org/en/reports/global/hdr2006/ (Cited 24 October 2008.)

2. Oxfam. Close the Gap, Solutions to the Indigenous Health Crisis facing Australia. Fitzroy: Oxfam; 2007. Available at: http://www.ahmrc.org.au/Downloads/CTG.pdf (Cited 24 October 2008.)

3. Australian Bureau of Statistics. The Health and Welfare of Australia's Aboriginal and Torres Strait Islander Peoples. Canberra: Australian Bureau of Statistics; 2008. Available at: http://www.abs.gov.au/ausstats/abs@.nsf/mf/4704.0/ (Cited 24 October 2008.) 